\title{
Is the canine corpus luteum an insulin-sensitive tissue?
}

\author{
Liza Margareth Medeiros de Carvalho Sousa', Renata dos Santos Silva1, \\ Vanessa Uemura da Fonseca1, Rafael Magdanelo Leandro1, Thiago Senna Di Vincenzo', \\ Ana Bárbara Alves-Wagner², Ubiratan Fabres Machado² and Paula de Carvalho Papa'
}

1Department of Surgery, School of Veterinary Medicine and Animal Science, University of São Paulo, São Paulo, Brazil 2Department of Physiology and Biophysics, Institute of Biomedical Sciences, University of São Paulo, São Paulo, Brazil
Correspondence should be addressed to P C Papa

Email ppapa@usp.br

\begin{abstract}
This study aimed to determine in the canine corpus luteum throughout the dioestrus (1) the influence of insulin on glucose uptake; (2) the regulation of genes potentially involved; and (3) the influence of hypoxia on glucose transporter expression and steroidogenesis, after treatment with cobalt chloride $\left(\mathrm{CoCl}_{2}\right)$. Glucose uptake by luteal cells increased 2.7 folds $(P<0.05)$ in response to insulin; a phenomenon related to increased expression of glucose transporter (GLUT) 4 and phosphorylation of protein kinase B (AKT). The gene expression of insulin receptor and SLC2A4 (codifier of GLUT4) genes after insulin stimulation increased on day 20 post ovulation (p.o.) and declined on day 40 p.o. $(P<0.05)$. Regarding potentially involved molecular mechanisms, the nuclear factor kappa B gene RELA was upregulated on days 30/40 p.o., when SLC2A4 mRNA was low, and the interleukin 6 (IL6) gene was upregulated in the first half of dioestrus, when $S L C 2 A 4$ mRNA was high. $\mathrm{CoCl}_{2}$ in luteal cell cultures increased the hypoxia-inducible factor HIF1A/HIF1A and the SLC2A4/GLUT4 expression, and decreased progesterone (P4) production and hydroxyl-delta-5-steroid dehydrogenase 3 beta (HSD3B) mRNA expression $(P<0.05)$. This study shows that the canine luteal cells are responsive to insulin, which stimulates glucose uptake in AKT/GLUT4-mediated pathway; that may be related to local activity of RELA and IL6. Besides, the study reveals that luteal cells under hypoxia activate HIF1A-modulating luteal function and insulin-stimulated glucose uptake. These data indicate that insulin regulates luteal cells' glucose disposal, participating in the maintenance and functionality of the corpus luteum.
\end{abstract}
Key Words
- corpus luteum
- glucose uptake
- insulin
- RELA/p65
- hypoxia

\section{Introduction}

The control of the function of canine corpus luteum (CL) is performed by complex mechanisms involving luteotrophic hormones, as well as autocrine and paracrine factors (Okkens et al. 1990, Onclin et al. 2000, Hoffmann et al. 2004, Kowalewski et al. 2011, Papa \& Hoffmann 2011, Kowalewski 2014).

According to Sonnack (M Sonnack, unpublished communications) the canine CL lasts 60 days after ovulation (p.o., day 0 is the day of ovulation), formation (day 0-15), maintenance or stage of secretory activity (day 15-45) and regression (day 45-60). During the CL development, a proper nutritional supply for luteal cells must be ensured, which is accomplished by glucose, the major energy substrate for ovarian activity, as demonstrated in granulosa cells of women with polycystic ovary syndrome (Kim et al. 2014) and endometrium (França et al. 2015), follicle and CL of cows, (Nishimoto et al. 2006). In CL of bovines, the

Published by Bioscientifica Ltd 
expression of solute carriers family 2 members (SLC2A) 1, 3 and 4, which codify the glucose transporters GLUT1, GLUT3 and GLUT4, respectively was reported, and the authors inferred that GLUT1 and GLUT3 would act as main carriers (Nishimoto et al. 2006). In this study, the authors proposed just a supportive role for GLUT4, in spite of (1) the $\sim 3$-fold increase observed in SLC2A4 expression through the CL development, (2) the fact that GLUT4 display the highest capacity of transport glucose (Uldry \& Thorens 2004) and (3) the fact that it can be rapidly regulated by insulin (Uldry \& Thorens 2004). In CL of dogs, our group has demonstrated a differential expression of glucose transporter 1 (SLC2A1/GLUT1), which accompanied hypoxia during the cycle (Papa et al. 2014), pointing out that the CL responds to physiological variations of oxygen tension during dioestrus (Nishimura \& Okuda 2015). However, nothing is known about the $S L C 2 A 4 /$ GLUT4 expression in CL of dogs.

The longer exposure to hypoxia was reported to increase transcription of the gene Slc2a1 in several cell types (Zhang et al. 1999). Later on, it was described that hypoxia also increases Slc2a3 and Slc2a4 expression in brain (Royer et al. 2000). Finally, it was described that Slc2a4 increases in response to muscle contraction, which reduces the intracellular oxygen tension, and that involves increased binding of the hypoxia-inducible factor 1A (Hif1a) into the Slc2a4 promoter region (Lima et al. 2009). Additionally, some studies further suggest that the Hif1a can also regulate the plasma membrane translocation of GLUT4 (Sakagami et al. 2014), known as the insulin-sensitive glucose transporter, primarily described in insulin-sensitive tissues, as adipose tissue and skeletal and cardiac muscles (James et al. 1988, Slot et al. 1991, Marette et al. 1992, Klip et al. 1996), reinforcing the effect of hypoxia upon regulation of GLUT4.

Although the CL requires high glucose uptake, works so far have explored neither the effect of insulin as inducer of glucose uptake in this organ nor whether physiological hypoxic conditions interfere with that effect when CL is forming, secreting or regressing. The transcriptional regulation of the Slc2a4 gene involves the control of several transcriptional factors including the enhancer Hif1 $a$ and the repressor RELA, former transcription factor p65, codified by the gene Rela (Furuya et al. 2013). Besides, interleukin 6 (IL6) has also been suggested as a repressor of Slc2a4 gene (Franckhauser et al. 2008, Poletto et al. 2015).

Thus, this study was designed to investigate the involvement of insulin on glucose uptake by luteal cells, as well as potentially involved positive and negative regulators of this effect. Given the importance of CL hypoxia-induced adaptation and its inductive role of glucose uptake, the effects of $\mathrm{CoCl}_{2}$, a mimicker of hypoxic environment and inducer of HIF1A (Metzen et al. 2003, Grasselli et al. 2005) on the expression of GLUT1/SLC2A1 and GLUT4/SLC2A4, as well as on luteal cells progesterone $(\mathrm{P} 4)$ production were also investigated.

\section{Materials and methods}

\section{Ethics statement}

Written consent was obtained from all owners of the dogs and the procedures were performed according to ethical principles approved by the Ethics Committee for the Use of Animals at the School of Veterinary Medicine and Animal Science, University of São Paulo, Brazil (Protocol numbers: 1432/2008 and 2080/2010).

\section{Dogs and sample collection}

Corpora lutea (CLs) were collected from 34 healthy cross-bred female dogs aged between 2 and 8 years via ovariohysterectomy (OSH) on specific days of dioestrus. After the onset of pro-oestrous bleeding, blood samples were collected on alternate days to determine P4 concentrations. When plasma $\mathrm{P} 4$ levels reached $5 \mathrm{ng} / \mathrm{mL}$, it was considered the day of ovulation (Concannon et al. 1989). For cell culture experiments, CLs were collected as follows: on days 20 (highest $\mathrm{P} 4$ plasma concentrations) and 40 (highest oestradiol (E2) plasma concentrations) post ovulation (p.o.) for (insulin treatment ( $n=4$ per day); on day 30 p.o. (full secretory activity) for glucose uptake assay $(n=3)$ and over dioestrus $(n=21)$ for the cobalt chloride treatment.

Anaesthetic and surgical procedures were performed as described previously (Papa et al. 2014). Before anaesthesia, blood samples $(5 \mathrm{~mL})$ were collected for metabolic and hormonal analyses. For immunohistochemistry, one CL per dog was fixed in $4 \%$ buffered formalin for $24 \mathrm{~h}$ and embedded in paraffin. For real-time PCR and Western blotting, one CL per dog per technique was immediately frozen in liquid nitrogen and stored at $-80^{\circ} \mathrm{C}$, and for cell culture, all CLs from each dog ( $n=4$ dogs per group) were kept in ice-cold phosphate-buffered saline (PBS) containing $1 \%$ penicillin-streptomycin-amphotericin B solution (A5955; Sigma-Aldrich).

Published by Bioscientifica Ltd 
Table 1 List of primers used for real time (TaqMan) PCR.

Primer
HIF1A - for
HIF1A - rev
HIF1A - probe
HSD3B - for
HSD3B - rev
HSD3B - probe
IL6 - for
IL6 - rev
IL6 - probe
INSR - for
INSR - rev
INSR - probe
RELA - for
RELA - rev
RELA - probe
SLC2A1 - for
SLC2A1 - rev
SLC2A1 - probe
SLC2A4 - for
SLC2A4 - rev
SLC2A4 - probe
PPIA

\begin{tabular}{|c|c|c|}
\hline Primer sequence & Accession number & Amplicon length \\
\hline $\begin{array}{l}\text { 5'-GCTGCTGGAGACACAATCATATCTT-3' } \\
\text { 5' ACATCATTATACAACGGAACTTCCTCAAG-3' }^{\prime} \\
\text { 5'-CAATGACACAGAAACTG-3' }\end{array}$ & XM860420 & 92 \\
\hline $\begin{array}{l}\text { 5'-GGGTACTCAGCTCCTGTTGGAA-3' } \\
\text { 5'-GCCACCTCTATGGTGCTGGTAT-3' } \\
\text { 5'-TGCCCAGGCTAGTGTGCCGATCTT-3' }\end{array}$ & NM_001010954.1 & 102 \\
\hline $\begin{array}{l}\text { 5'-AAAGAGCAAGGTAAAGAATCAGGATG-3' } \\
\text { 5'-GCAGGATGAGGTGAATTGAAGTGTATT-3' } \\
\text { 5'-GTGATGTCTGCTCGGTAAG-3' }\end{array}$ & XM_843327-1 & 148 \\
\hline $\begin{array}{l}\text { 5'-GCAGGARGAGGTGAATTGTTGTG-3' } \\
\text { 5'-CCGAGACCTCAGTTTCCCCA-3' } \\
\text { 5'-AAAACGAGGCCCGAGGATTT-3' }\end{array}$ & AIBJWTL_R & 108 \\
\hline $\begin{array}{l}\text { 5'-GCAGAAAGAGGACATTGAAGTGTATT-3' } \\
\text { 5'-TCGGTGTACATCAGCTTGAGAAA-3' } \\
\text { 5'-CCAGGCTGGGAGGCCCGA-3' }\end{array}$ & NW_876266-1 & 118 \\
\hline $\begin{array}{l}\text { 5'-CAGCCAGAGTCCCCTGTATCTA-3' } \\
\text { 5'-GTCCCCACCTTCAGGTACTG-3' } \\
\text { 5'-CACCCCAGACTTCACC-3' }\end{array}$ & XM_539554 & 99 \\
\hline $\begin{array}{l}\text { 5'-GCCTGCCAGAAAGAGTCTGAAG-3' } \\
\text { 5'-GCTTCCGCTTCTCCTCCTT-3' } \\
\text { 5'-CAGTGCCCCAGATACAT-3' } \\
\text { Pre-designed assay from Life Technologies Pro }\end{array}$ & NM_001159327 & 91 \\
\hline
\end{tabular}

\section{Luteal cell culture}

CL samples were immediately washed with fresh PBS containing 1\% antibiotic-anti-mycotic solution (A5955, Sigma-Aldrich), and cut into small pieces. These pieces were transferred to $1 \mathrm{~mL}$ Dulbecco's modified Eagle medium (DMEM) supplemented with 10\% foetal bovine serum (FBS; Sigma-Aldrich), 1\% L-glutamine (Sigma-Aldrich), $20 \mathrm{mM}$ HEPES (Sigma-Aldrich), 1\% antibiotic-anti-mycotic solution and $1 \mathrm{mg} / \mathrm{mL}$ collagenase type 1 (C0130; SigmaAldrich). The incubation lasted for $1 \mathrm{~h}$ under stirring (60 rotations $/ \mathrm{min}$ ) at $37^{\circ} \mathrm{C}$. The suspension was centrifuged at $200 \boldsymbol{g}$ for $10 \mathrm{~min}$, re-suspended in DMEM and filtered through a cell strainer (70 $\mu \mathrm{m}$; BD Falcon; BD Biosciences, Durham, NC, USA). The filtrate was centrifuged at $200 \boldsymbol{g}$ for $10 \mathrm{~min}$, re-suspended in an erythrocyte lysis buffer (0.16 M NH $\mathrm{NH}_{4} \mathrm{Cl}, 0.01 \mathrm{M}$ Tris- $\mathrm{HCl} \mathrm{pH}$ 7.2-7.4) diluted in $\operatorname{DMEM}(\mathrm{v} / \mathrm{v})$ for $10 \mathrm{~min}$, centrifuged at $200 \boldsymbol{g}$ for $10 \mathrm{~min}$, and re-suspended in DMEM. For glucose uptake study, luteal cells were seeded in 6-well plates, whereas for insulin and cobalt chloride $\left(\mathrm{CoCl}_{2}\right)$ treatments, cells were seeded in 24-well plates. Furthermore, for GLUT1 and GLUT4 immunocytochemistry, luteal cells were seeded in 24-well plates containing coverslips and fixed with 95\% methanol. Subsequently, cells were kept in an incubator at $37^{\circ} \mathrm{C}$ and $5 \% \mathrm{CO}_{2}$. After ten days of culture (90\% confluence), the cells were subjected to serum-free medium for $24 \mathrm{~h}$ (except for glucose uptake) and treated following different protocols as described below.

\section{Determination of 2-deoxyglucose uptake}

Glucose uptake analysis was performed as described previously (Campello et al. 2012), using 2-deoxy-[1,2$\left.{ }^{3} \mathrm{H}\right]$-D-glucose $0.2 \mathrm{mCi} \cdot \mathrm{mL}^{-1}$; Perkin Elmer) for $5 \mathrm{~min}$, after

Table 2 List of antibodies used for immunohistochemistry and Western blotting.

\begin{tabular}{|c|c|c|}
\hline Antibodies & Isotype & Epitope \\
\hline GLUT1 & Goat polyclonal IgG & C-terminus human \\
\hline GLUT4 & Rabbit polyclonal IgG & C-terminus human \\
\hline HIF1A & Rabbit polyclonal lgG & $\begin{array}{l}\text { Human HIF1A amino acids } \\
(432-528)\end{array}$ \\
\hline IL6 & Mouse monoclonal IgG2a & $\begin{array}{l}\text { Recombinant full length } \\
\text { human protein }\end{array}$ \\
\hline INSR & Rabbit polyclonal IgG & N-terminus human \\
\hline P65 & Mouse monoclonal IgG3 & Human p65 \\
\hline ACTB & Mouse monoclonal & N-terminal \\
\hline
\end{tabular}

\begin{tabular}{ccc}
\hline Dilution IHC & & Dilution WB \\
\cline { 1 - 1 } 0.5 & & 0.4 \\
- & & 0.4 \\
& & \\
0.3 & & 0.4 \\
0.1 & & 0.5 \\
0.3 & & 0.4 \\
- & 0.4
\end{tabular}

\begin{tabular}{l} 
Supplier (order $\mathrm{n}^{\circ}$ ) \\
\hline Santa Cruz (C-20; sc-1605) \\
Millipore (07-1404) \\
Novus Biologicals (NB100-134) \\
Abcam (ab 9324) \\
Abcam (ab 78424) \\
Millipore (MAB 3026) \\
Sigma-Aldrich (Clone AC-15; A1978)
\end{tabular}


a 20-min stimulus with $100 \mathrm{nM}$ insulin. Incorporated radioactivity was measured, results were calculated and expressed as both cpm/ $\mu$ g protein and cpm/106 cells.

\section{Effect of insulin on luteal INSR and SLC2A4 expression}

Luteal cells from CLs obtained on days 20 and 40 p.o. were maintained in DMEM without serum for $24 \mathrm{~h}$. These cells were then treated with 100 nM insulin (I6634; SigmaAldrich). After $24 \mathrm{~h}$, the culture medium was removed, TRIzol was added to the cells and they were collected and processed for real-time PCR analysis.

\section{Gene expression assessed by real-time PCR}

Total RNA extraction was performed using the TRIzol reagent, following manufacturer's instructions (Life Technologies). RNA concentration was measured using the NanoDrop 2000 (Thermo Fisher Scientific), whereas the purity and integrity of the samples were determined using $2 \%$ agarose gel.

Real-time PCR (qPCR) was carried out as described previously (Kowalewski et al. 2006). Briefly, the total RNA was subjected to reverse transcription using the SuperScript III kit, according to manufacturer's instructions (Life Technologies). PCR analyses were performed with an automated fluorometer (ABIPrism 7500, Life Technologies), using 96-well optical plates. Each sample (25 ng total RNA) was analyzed at least in duplicates. Primers (Table 1) were ordered from Applied Biosystems (Life Technologies). Relative quantification was performed by normalizing the target genes signals with cyclophilin A signal (as reference gene), as determined by the NormFinder software (Andersen et al. 2004). The amplification efficiency was analyzed by the LinRegPCR programme (Ramakers et al. 2003), followed by Pfaffl's method (Pfaffl 2001).

\section{Immunohistochemistry for INSR, GLUT4, IL6 and p65 and immunocytochemistry for GLUT4}

Immunohistochemistry and immunocytochemistry were performed based on procedures described previously (Mariani et al. 2006). Sections ( $2 \mu \mathrm{m}$ thick) from two CL samples per dog, or cells grown over coverslips, analyzed. Primary antibodies are presented in Table 2. Negative controls were established by using the corresponding isotype control (normal rabbit IgG; Santa Cruz Biotechnology) or by replacing the primary antibody with

buffer in subsequent reactions. Mouse skeletal muscle was used as a positive control for INSR and GLUT4, and human carcinoma tissue was used as a positive control for p65 and IL6.

\section{Protein expression assessed by Western blotting}

For total protein extraction, isolated cells and tissue samples were homogenized in NET-2 lysis buffer (50 mM Tris- $\mathrm{HCl}$ (pH 7.4), $300 \mathrm{mM} \mathrm{NaCl}$ and $0.05 \%$

\begin{tabular}{llccc}
\hline A 2 min insulin (100 nM) stimulus: & Basal & Insulin & P \\
\hline Total AKT (AU/ug protein) & $10.0 \pm 0.32$ & $10.8 \pm-.38$ & NS \\
Phospho AKT (AU/ug protein) & $10.1 \pm 1.9$ & $42.9 \pm 1.17$ & $<0.001$ \\
Glucose uptake (cpm/ug protein) & $2.05 \pm 0.8$ & $5.73 \pm 0.5$ & $<0.01$ \\
Glucose uptake (cpm/10 ${ }^{6}$ cels) & $79.6 \pm 35.3$ & $212.5 \pm 34.5$ & $<0.05$ \\
\hline
\end{tabular}

B

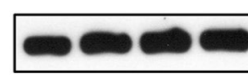

Total AKT
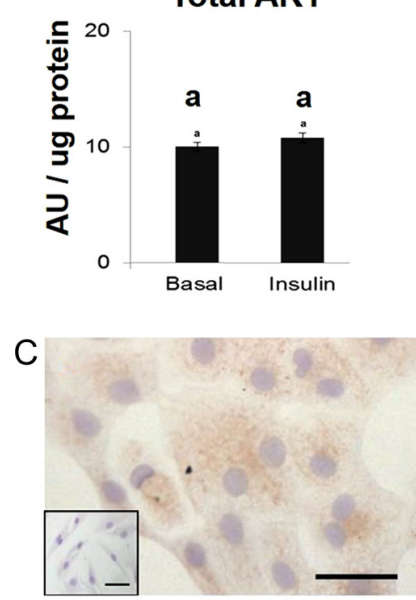

E

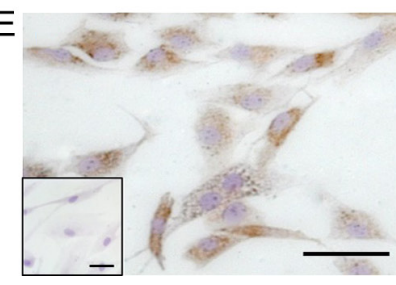

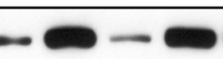

Phosphorylated AKT

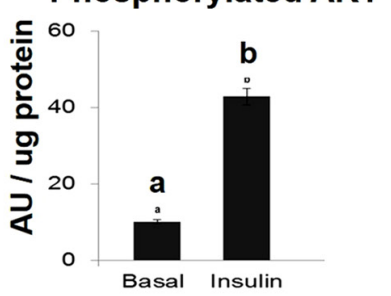

$\mathrm{D}$

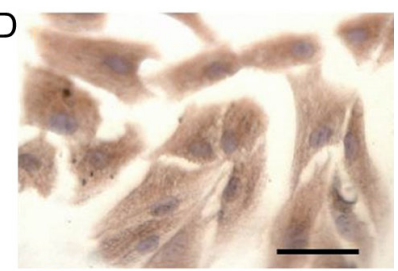

F

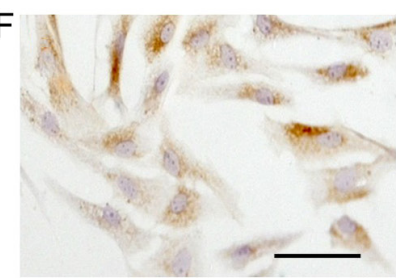

Figure 1

Glucose uptake, AKT, GLUT4 and GLUT1 analyses in canine luteal cells from 30-day p.o. corpora lutea, stimulated or not (basal) with insulin for $20 \mathrm{~min}$. (A) Glucose uptake. (B) Protein expression of phosphorylated AKT (phospho-AKT) and total AKT. Immunocytochemistry for GLUT4 (C and D) and GLUT1 ( $E$ and F), before ( $C$ and $E$ ) and after ( $D$ and $F$ ) the addition of insulin. Positive signals were observed, as indicated by the brown colour in the luteal cells. Data are mean \pm S.E.M. of 4 wells for glucose uptake and 3 wells for AKT per group. In each well, the cells are from CLs from different animals. Different letters represent significant difference $(P<0.001)$. Bars $=50 \mu \mathrm{m}$. Inserts $=$ negative controls. 
NP-40) containing $1 \mu \mathrm{L} / \mathrm{mL}$ protease inhibitor cocktail (Sigma-Aldrich), and centrifuged at $10,000 \boldsymbol{g}$ for $10 \mathrm{~min}$ at $4^{\circ} \mathrm{C}$. The supernatant was used as a total cellular extract. Nuclear protein extraction was prepared based on procedures described previously (Andrews \& Faller 1991). The total protein concentration in the samples was determined by the Bradford method (Bradford 1976).

Whole cellular and nuclear extracts ( 25 or $30 \mu \mathrm{g}$ ) were resolved by sodium dodecyl sulphate-polyacrylamide gel electrophoresis (SDS-PAGE) on 10\% (HIF1A) and 12\% (GLUT1, GLUT4, INSR, IL6 and p65) gels and electrophoretically transferred onto a nitrocellulose membrane (Fátima et al. 2013). Immunodetection was performed using the primary antibodies listed in Table 1, and peroxidase-labelled anti-rabbit, anti-mouse and anti-goat antibodies at 1:7500 dilution as secondary antibodies (Amersham Biosciences, GE Healthcare Life Science). The blots were visualized using an Enhanced Chemiluminescence (ECL) Kit (Amersham Biosciences, GE Healthcare Life Science) and images were captured by ChemiDoc MP Image system (Bio-Rad Laboratories). Beta-actin (ACTB) was used as loading control.

\section{Cobalt chloride $\left(\mathrm{CoCl}_{2}\right)$ treatment}

Luteal cells collected on days 10, 30 and 60 p.o. were treated for $24 \mathrm{~h}$ with $500 \mu \mathrm{M}$ cobalt chloride $\left(\mathrm{CoCl}_{2}\right.$; Sigma-Aldrich). The concentration was chosen based on a preliminary dose-response curve. After the treatment, the medium was collected and stored at $-20^{\circ} \mathrm{C}$ until progesterone determination by validated chemiluminescence immunoassay (Papa et al. 2014). Finally, the cells were processed for RNA or protein extraction as described above.
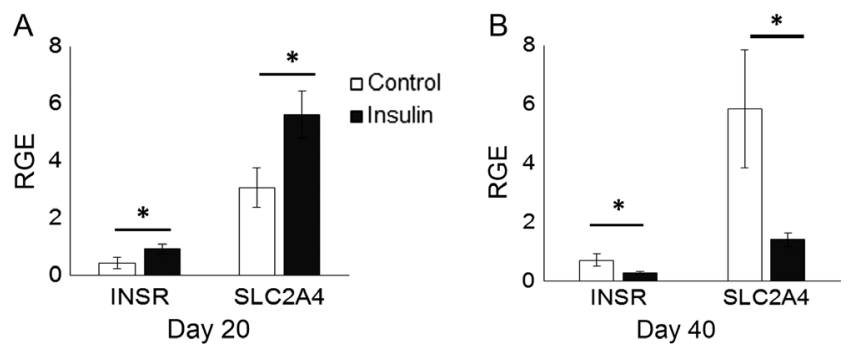

Figure 2

Gene expression of the insulin receptor (INSR) and the solute carrier 2A4 (SLC2A4) in canine luteal cells from 20-day (A) and 40-day (B) p.o. and treated with $100 \mathrm{nM}$ insulin for $24 \mathrm{~h}$. Relative expression (RGE) of target genes was normalized by cyclophilin A. Data are mean \pm s.E.M. of cells from 4 CLs from different animals in each day. Asterisks indicate significant differences $(P<0.05)$.

\section{Statistical analysis}

All the experiments were performed at least 3 times with a minimum of three replicates. Data were tested according to their homogeneity and normality of variances, transformed to square to normalize the distributions and presented as mean \pm S.E.M. Statistical differences between control and treated groups were calculated using unpaired $t$-test with Welch's correction. In each analysis, critical significance level was $P<0.05$. All calculations were performed using the GraphPad Prism 5 programme (GraphPad Software).

\section{Results}

\section{Glucose uptake by luteal cells under insulin stimulation}

To investigate the role of insulin in the canine CL, we tested the capacity of luteal cells from 30-day p.o. CLs to uptake glucose in response to insulin. Glucose uptake was 2.7fold increased after insulin stimulus (Fig. 1A), expressed by both micrograms of protein $(P<0.01)$ and number of cells $(P<0.05)$. Additionally, we verified that despite unchanged total AKT content, insulin increased $(P<0.001)$ the AKT phosphorylation (Fig. 1A and B). GLUT4 and GLUT1 staining revealed that both were present in luteal cells; however, only GLUT4 showed a qualitative signal increase in the presence of insulin (Fig. 1C and D).
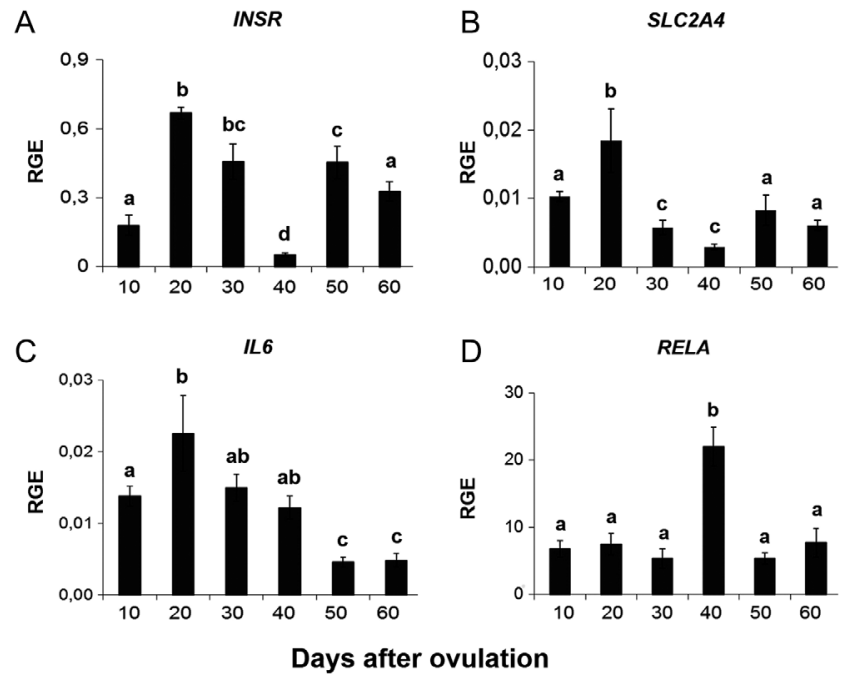

Figure 3

INSR (A), SLC2A4 (B), IL6 (C) and RELA (D) mRNA expression in canine corpora lutea (CLs) from 10 to 60 days after the ovulation, determined by real-time (TaqMan) PCR. Relative expression (RGE) of target genes was normalized by cyclophilin A. Data are mean \pm S.E.M. of $4 \mathrm{CLs}$ from different animals. Bars with different letters represent significant differences $(P<0.05)$.

Published by Bioscientifica Ltd. 


\section{Effect of insulin on INSR and SLC2A4 gene expression in luteal cells}

After determining the ability of luteal cells to alter the insulin-stimulated glucose uptake, we investigated the effect of 24-h insulin treatment upon the insulin receptor (INSR) and the SLC2A4 gene expression in luteal cells from 20-day and 40-day p.o. corpora lutea. The results show that in luteal cells from day 20 p.o. insulin increased the expression of INSR and SLC2A4 (Fig. 2A), whereas in cells from day 40 p.o., the insulin effect was completely opposed (Fig. 2B).

\section{INSR, SLC2A4, IL6 and RELA mRNA expression in the $\mathrm{CL}$ throughout dioestrus}

The mRNA expression of INSR (Fig. 3A) and SLC2A4 (Fig. 3B) in luteal tissue was the lowest on day 40 p.o. $(P<0.05)$, a moment in which the RELA (Fig. 3D) expression was the highest. Besides, the highest expression of INSR and SLC2A4 was observed on day 20 p.o., when
RELA expression was low. In general, the results show that INSR and SLC2A4 expression were parallely regulated throughout the dioestrus, and in opposition to that observed in the RELA expression. Finally, the highest expression of IL6 (Fig. 3C) was concomitant with the highest levels of INSR and SLC2A4 (20 p.o.); however, IL6 expression in other moments of the dioestrus seems to not correlate with the INSR or SLC2A4 expression.

\section{INSR, GLUT4, IL6 and p65 protein expression in the $\mathrm{CL}$ throughout dioestrus}

The INSR, GLUT4, IL6 and p65 proteins were detected by immunohistochemistry in luteal cells at all studied stages (Fig. 4). To verify whether the mRNA regulations observed in the canine CLs were accompanied by changes in the respective proteins, Western blotting analysis of the proteins was performed. INSR expression (Fig. 5A) was higher on day 10 p.o., which was also observed by

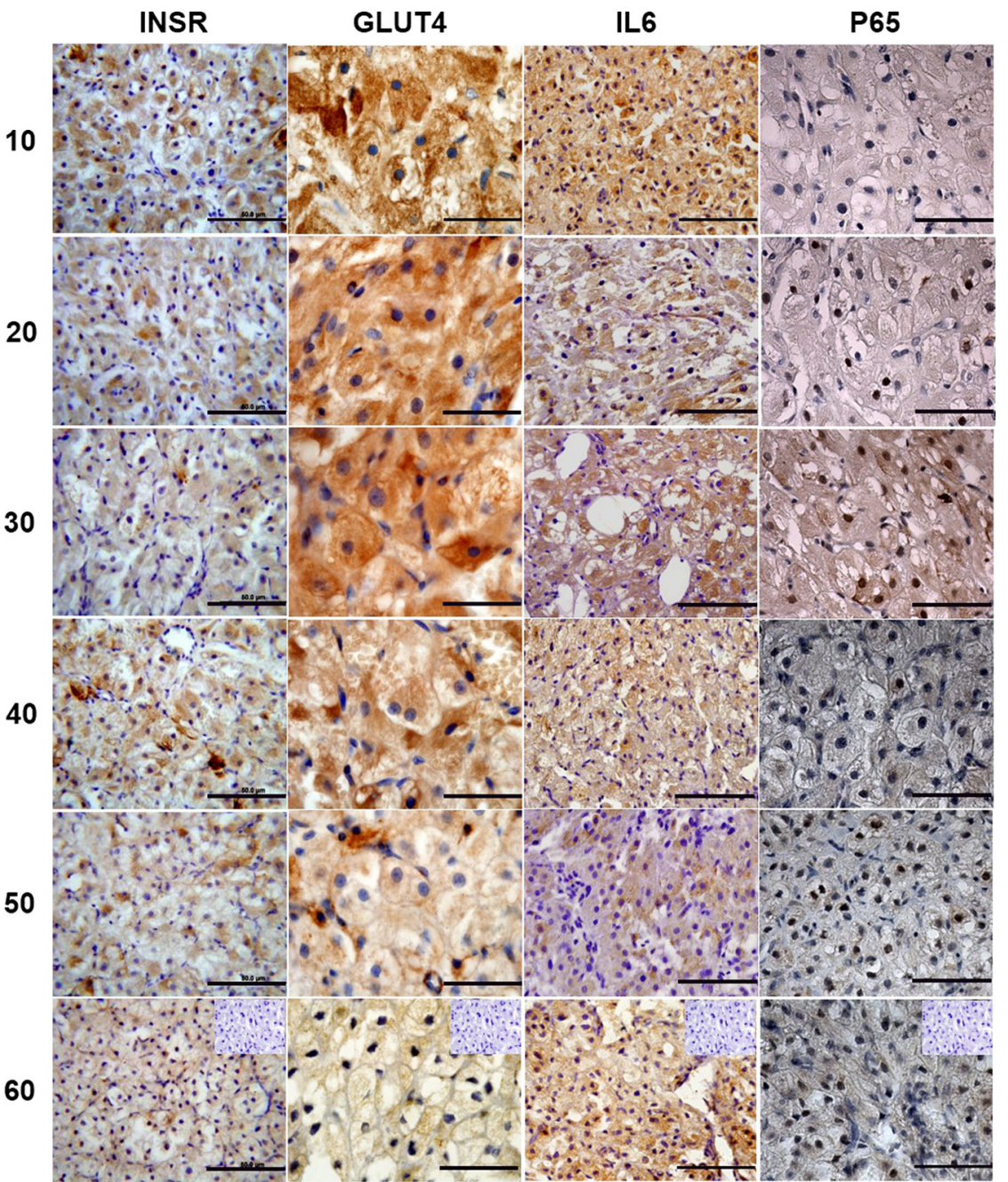

\section{Figure 4}

Immunohistochemical detection of INSR, GLUT4, IL6 and p65 in canine corpora lutea (CLs) from 10 to 60 days after ovulation. Positive INSR, GLUT4, IL6 and p65 signals were observed at all stages of CLs. Inserts = negative controls. Bars $=50 \mu \mathrm{m}$. http://joe.endocrinology-journals.org
DOI: 10.1530/JOE-16-0173
๑) 2016 Society for Endocrinology Printed in Great Britain 
A

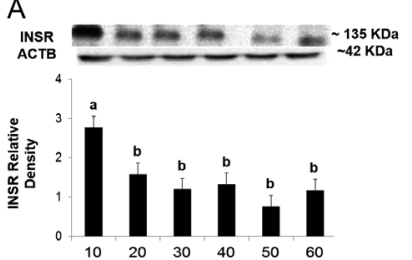

$\mathrm{C}_{\mathrm{ILC}}=-\cdots-\sim-26 \mathrm{KDa}$

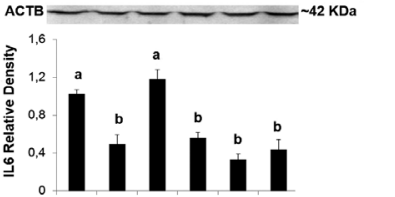

$0 \underbrace{}_{10} \square_{20} \underbrace{}_{30} \underbrace{}_{40} \underbrace{}_{50}$

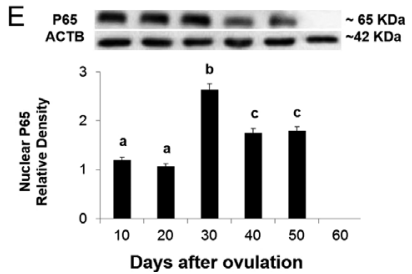

Figure 5

Expression of INSR (A), GLUT4 (B), IL6 (C), total p65 (D) and nuclear p65 (E) proteins in canine corpora lutea (CLs) from 10 to 60 days after ovulation. In each panel, representative Western blotting images are shown. Results were to ACTB expression. Data are expressed as the mean \pm S.E.M. of $4 \mathrm{CLS}$ from different animals. Different letters indicate a significant difference $(P<0.05)$.

immunohistochemistry. GLUT4 expression (Fig. 5B) showed a peak on day 30 p.o., which was also observed by immunohistochemistry. However, these regulations were not in parallel with the mRNA regulation, indicating the occurrence of post-transcriptional modulations.

We also studied the proteins of the above-mentioned genes that are known to regulate GLUT4 expression either
A

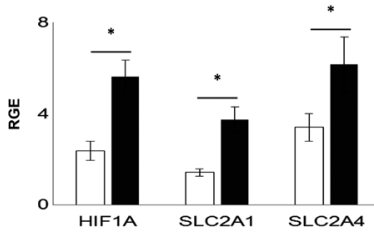

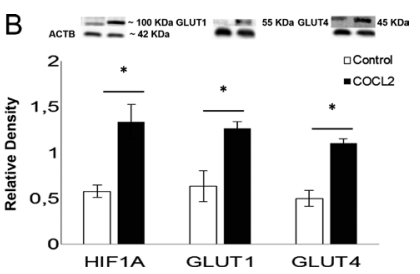

Figure 6

Expression of HIF1A, SLC2A1 and SLC2A4 mRNAs (A) and HIF1A, GLUT1 and GLUT4 proteins (B) in canine luteal cells 24-h treated with $500 \mu \mathrm{M}$ $\mathrm{CoCl}_{2}$. Gene expression was analyzed by qPCR and proteins by Western blotting in a whole cellular homogenate. Relative expression (RGE) of target genes was normalized by cyclophilin A. Representative immunoblots are shown. B-actin (ACTB) was used as loading control. Data are mean \pm S.E.M. of 12 plates from 4 different animals from days 10 , 30 and 60 p.o. Different letters represent significant difference $(P<0.001)$.
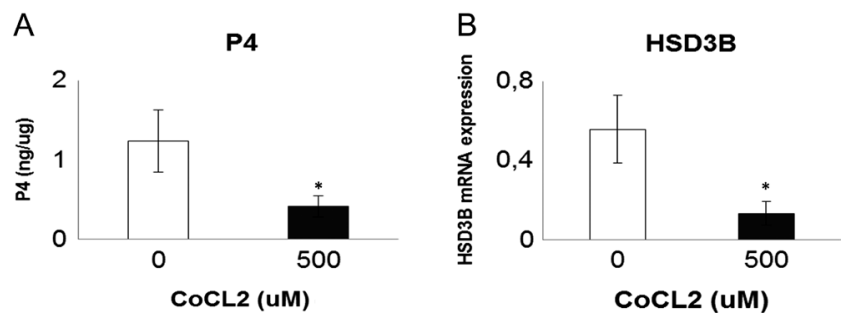

Figure 7

Progesterone secretion (A) to the medium (ng $\mu \mathrm{g}^{-1}$ de protein) and (B) $H S D 3 B$ mRNA expression (B) by canine luteal cells $24-\mathrm{h}$ treated with $500 \mu \mathrm{M} \mathrm{CoCl}_{2}$. Data are mean \pm S.E.M. of 12 plates from 4 different animals from days 10,30 and 60 p.o. Asterisk represents significant difference $(P<0.05)$.

positively (IL6) or negatively (p65). Quantification of IL6 showed the highest expression at day 30 p.o., decreasing thereafter (Fig. 5C; $P<0.05$ ); similar to that observed in the immunohistochemistry. We quantified p65 in a total cellular extract and nuclear samples of luteal cells (Fig. 5D and E), and observed that in both the p65 expression was highest on day 30 p.o. This high level of expression was followed by a decline on day 50 p.o. After day 50 p.o., nuclear p65 was undetectable by Western blotting.

\section{Cobalt chloride stimulates HIF1A/HIF1A, SLC2A1/GLUT1} and SLC2A4/GLUT4 expression and inhibits progesterone production in canine luteal cells

It is well determined that CL physiologically undergoes hypoxia; thus, we investigated the effect of $\mathrm{CoCl}_{2}$ on luteal cells obtained on days 10, 30 and 60 p.o. Since no effect of the day (10, 30, 60 p.o.) was observed after statistical analysis over $\mathrm{P} 4$ production and hydroxyl-delta-5-steroid dehydrogenase 3 beta (HSD3B) mRNA expression, we considered just the effect of treatment, that is, control cells and $\mathrm{CoCl}_{2}$-treated cells. As expected, $\mathrm{CoCl}_{2}$ increased the expression of HIF1A mRNA and HIF1A protein, and that was accompanied by similar increase in the mRNA and protein expression of SLC2A1/GLUT1 and SLC2A4/ GLUT4 (Fig. 6).

Additionally, 24-h $\mathrm{CoCl}_{2}$ treatment of the luteal cells (Fig. 7) reduced both the $\mathrm{P} 4$ secreted to the medium, and the $H S D 3 B$ mRNA expression, which codifies the key enzyme for P4 synthesis.

\section{Discussion}

To the best of authors' knowledge, this is the first study to present data that luteal cells are able to uptake glucose

Published by Bioscientifica Ltd. 
under insulin stimulus in an AKT-mediated way, and followed by GLUT4 protein increase. In addition, expression of genes related to insulin biological effectiveness as INSR, SLC2A4, IL6 and RELA has been characterized. Besides, the influence of mimicking low $\mathrm{O}_{2}$ concentrations on the expression of HIF1A/HIF1A, SLC2A1/GLUT1 and SLC2A4/GLUT4 mRNAs and proteins, as well as on the $H S D 3 B$ mRNA expression and P4 production throughout dioestrus was also analyzed.

GLUT4 expression, the limiting step of insulinstimulated glucose uptake, was highest in the middle of the CL maintenance period (day 30 p.o.); thus, that moment was chosen to confirm the hypothesis that canine luteal cells are sensitive to insulin. In fact, insulin induced a 2.7-fold increase in the glucose uptake within 20 minutes, similar to that described in classical insulinsensitive tissues such as adipose tissue and skeletal muscle (James et al. 1988, Klip \& Pâquet 1990, Slot et al. 1991, Marette et al. 1992). Besides, in response to insulin, phospho-AKT was 4-fold increased, indicating a classic activation of insulin signalling, as described previously for insulin-induced glucose uptake by oocytes and cumulus cells (Purcell et al. 2012).

As P4 and E2 plasma levels variate throughout dioestrus, and E2 has been reported to be able to modulate SLC2A4/GLUT4 expression, we tested the effect of insulin on INSR and SLC2A4 genes' expression in luteal cells obtained from CLs harvested at the limits of the maintenance/secretory phase; that is at days 20 and 40 p.o., when the highest levels of $\mathrm{P} 4$ and E2, respectively, were observed. Interestingly, insulin increased the SLC2A4 and INSR mRNAs on day 20, but decreased them on day 40 p.o., suggesting that the previous hormonal ambient of the CLs modulated the insulin effect.

SLC2A4 mRNA and GLUT4 protein have been shown to be regulated by E2, and that is differently modulated by the oestrogen receptors 1 (ESR1) and 2 (ESR2), as demonstrated in adipose and muscular tissues (Barros et al. 2009). Using knockout mice for ESR1 and ESR2, Barros and collaborators reported that ESR1 increases, whereas ESR2 represses the expression of GLUT4 (Barros et al. 2009). Using selective ERS1 and ESR2 agonists in 3T3L1 adipocytes, the enhancer effect of ESR1 and the repressor effect of ESR2 on SLC2A4/GLUT4 expression were confirmed (Campello et al. 2012). Therefore, the effect of E2 upon SLC2A4/GLUT4 expression may depend on the balance between ESR1 and ESR2. The expression of ESR1 and ESR2 in canine CL over dioestrus has been already described (Hoffmann et al. 2004, Papa \& Hoffmann 2011). During the first half of dioestrus (formation and maintenance/secretory phase, ESR1 is more abundant decreasing in the second half (end of maintenance and regression phases). On the other hand, ESR2 remains unchanged over dioestrus. Associating these findings to this study, we can infer that insulin is able to increase expression of SCL2A4 on day 20 p.o. probably due to the predominant action of ESR1, despite low E2 levels (Papa et al. 2014). Conversely, on day 40 p.o. (end of the maintenance/secretory phase), high E2 levels and predominant action of ESR2 contribute to the repressive effect of insulin on SLC2A4 expression. Therefore, these data we reported for luteal cells regarding insulin effect on SLC2A4 gene seem to be related to E2/ESR1/ESR2 balance, similarly to those described in the adipose and muscle tissues.

Regarding the INSR gene regulation and gonadal hormones, E2 has already been proposed as enhancer of INSR mRNA expression in hypothalamus (Clegg et al. 2006), however, nothing is known about either its hormonal regulation in the female reproductive organs or the ESR1/2 participation.

Comparing the effects of insulin in cultured luteal cells, similar regulations were observed directly in the CLs harvested throughout the dioestrus. SLC2A4 and INSR mRNAs were highest at day 20, and lowest at day 40 , suggesting that endogenous insulin is playing the same role that was observed in vitro in luteal cells, and in accordance with the ESR1/ESR2 balance.

Regulation of SLC2A4 expression is dependent on the binding activity of nuclear factor kappa B (NFKB), mainly the isoforms NFKB1 and RELA, to the promoter region of $S L C 2 A 4$ in muscle and adipose tissues. Besides, NFKB-binding activity also participates on the ESR1- and ESR2-mediated effects of E2 in adipocytes (Campello et al. 2012). Not surprisingly, when evaluating RELA expression in canine CL, we found an upregulation of this gene and respective protein on day 40 p.o., thus suggesting the same regulation of SLC2A4 mRNA that has been described for NFKB in adipose and skeletal muscle tissues or cells (Silva et al. 2005, Campello et al. 2012, Furuya et al. 2013).

Although some studies have demonstrated a negative effect of IL6 on SLC2A4/GLUT4 expression in adipocytes (Lagathu et al. 2003, Poletto et al. 2015), IL6-induced enhancer effect on SLC2A4/GLUT4 expression was reported in skeletal muscle cells (Al-Khalili et al. 2006), indicating that IL6 regulations may vary accordingly to the cell type. Our data support the hypothesis that in luteal cells, IL6 plays an enhancer effect on SLC2A4/ GLUT4 during formation/maintenance phases of dioestrus, as the upregulation of IL6 mRNA and protein

Published by Bioscientifica Ltd. 
were highest in the days 20 and 30 p.o., respectively. Besides, we must consider that the variations in IL6 production observed in CLs may be participating on the regulation of ESR1/ESR2 expression, as it has already been reported in a cell line A2780 from human ovarian carcinoma (Wang et al. 2014).

Hypoxia can be considered a physiological state for luteal cells (Nishimura \& Okuda 2015) and highly influences the cellular homeostasis. Cells increase HIF1A (hypoxia-inducible factor 1A) expression as the oxygen tension decreases (Tarhonskaya et al. 2015), and the canine CL response to hypoxia and HIF1A expression has been correlated to increased SLC2A1/GLUT1 expression (Papa et al. 2014). The influence of HIF1A in SLC2A4/GLUT4 expression has also been described in skeletal muscle cells (Silva et al. 2005, Lima et al. 2009), in which reduced oxygen tension activates HIF1A and enhances SLC2A4 transcription. This work showed that $S L C 2 A 4$ expression parallels that of SLC2A1 in canine CL (Papa et al. 2014) over dioestrus, and cells subjected to $\mathrm{CoCl}_{2}$ increased expression of HIF1A, SLC2A1 and SLC2A4 mRNAs and respective proteins. In fact, HIF1A is able to bind to an E-box domain present in the promoter region of SLC2A4 gene, and once activated by reduction in intracellular oxygen tension, as in response to contraction of skeletal muscle, its binding activity increases enhancing SLC2A4 transcription (Lima et al. 2009). Thus, strong regulations observed in GLUT1 and GLUT4 expression, as well as in glucose uptake in CL, seem to be highly related to cellular oxygen disposal througout the dioestrus.

Altogether, our results point towards the ability of luteal cells to uptake glucose in response to insulin stimulus, which includes insulin in the list of luteotrophic factors. Additionally, the data revealed that INSR and GLUT4 expression in luteal cells varies according to the phase of CL lifespan and that can be related to IL6 and RELA/p65 expression. Besides, the study demonstrates that $\mathrm{CoCl}_{2}$ enhances SLC2A4 and HIF1A mRNA expression in luteal cells, indicating that hypoxia plays an important role in the regulation of SLC2A4/GLUT4 expression during the development of CL.

\section{Declaration of interest}

The authors declare that there is no conflict of interest that could be perceived as prejudicing the impartiality of the research reported.

\section{Funding}

This work was supported by FAPESP (grant numbers 2008/54835-8, 2010/07373-9 and 2011/17768-3) and CAPES (025/2011).

\section{Author contribution statement}

All authors participated in the experimental design, data analysis and interpretation, and revised the manuscript for intellectual content. L M M C S performed canine luteal cell culture, $\mathrm{CoCl}_{2}$ experiments and wrote part of the manuscript. R S S performed canine luteal cell culture, insulin stimulation experiments and wrote part of the manuscript. R M L and T S D V performed ovariohysterectomies and C L sample collection. A B A-V performed glucose uptake analysis in cultured canine luteal cells. U F M critically read the manuscript and participated in very fruitful discussions. P C P conceived the studies, performed IL6 and RELA/p65 analyses and wrote the manuscript.

\section{Acknowledgements}

The authors thank Dr Ivana Carvalho from CEPRA NGO and the Zoonosis Control Center of Guarulhos for providing access to the dogs and keeping them in nice atmosphere. We thank all dogs' guardians, who agreed to dispose ovarian tissue for this study.

\section{References}

Al-Khalili L, Bouzakri K, Glund S, Lonnqvist F, Koistinen HA \& Krook A 2006 Signaling specificity of interleukin-6 action on glucose and lipid metabolism in skeletal muscle. Molecular Endocrinology 20 3364-3375. (doi:10.1210/me.2005-0490)

Andersen CL, Jensen JL \& Ørntoft TF 2004 Normalization of real-time quantitative reverse transcription-PCR data: a model-based variance estimation approach to identify genes suited for normalization, applied to bladder and colon cancer data sets. Cancer Research 64 5245-5250. (doi:10.1158/0008-5472.CAN-04-0496)

Andrews NC \& Faller DV 1991 A rapid micropreparation technique for extraction of DNA-binding proteins from limiting numbers of mammalian cells. Nucleic Acids Research 19 2499. (doi:10.1093/ nar/19.9.2499)

Barros RP, Gabbi C, Morani A, Warner M \& Gustafsson JA 2009 Participation of ERalpha and ERbeta in glucose homeostasis in skeletal muscle and white adipose tissue. American Journal of Physiology: Endocrinology and Metabolism 297 E124-E133. (doi:10.1152/ajpendo.00189.2009)

Bradford MM 1976 A rapid and sensitive method for the quantitation of microgram quantities of protein utilizing the principle of protein-dye binding. Analytical Biochemistry 72 248-254. (doi:10.1016/00032697(76)90527-3)

Campello RS, Alves-Wagner AB, Lucas TF, Mori RC, Furuya DT, Porto CS \& Machado UF 2012 Estrogen receptor 1 agonist PPT stimulates Slc2a4 gene expression and improves insulin-induced glucose uptake in adipocytes. Current Topics in Medicinal Chemistry 12 2059-2069. (doi:10.2174/156802612804910197)

Clegg DJ, Brown LM, Woods SC \& Benoit SC 2006 Gonadal hormones determine sensitivity to central leptin and insulin. Diabetes $\mathbf{5 5}$ 978-987. (doi:10.2337/diabetes.55.04.06.db05-1339)

Concannon PW, McCann JP \& Temple M 1989 Biology and endocrinology of ovulation, pregnancy and parturition in the dog. Journal of Reproduction and Fertility Supplements 39 3-25.

Franckhauser S, Elias I, Rotter Sopasakis V, Ferre T, Nagaev I, Andersson CX, Agudo J, Ruberte J, Bosch F \& Smith U 2008 Overexpression of Il6 leads to hyperinsulinaemia, liver inflammation and reduced body weight in mice. Diabetologia 51 1306-1316. (doi:10.1007/s00125-008-0998-8)

França MR, Mesquita FS, Lopes E, Pugliesi G, Van Hoeck V, Chiaratti MR, Membrive CB, Papa PC \& Binelli M 2015 Modulation of periovulatory endocrine profiles in beef cows: consequences for endometrial glucose transporters and uterine fluid glucose levels. Domestic Animal Endocrinology 50 83-90. (doi:10.1016/j.domaniend.2014.09.005) 
Furuya DT, Neri EA, Poletto AC, Anhê GF, Freitas HS, Campello RS, Rebouças NA \& Machado UF 2013 Identification of nuclear factor-кB sites in the Slc2a4 gene promoter. Molecular and Cellular Endocrinology 370 87-95. (doi:10.1016/j.mce.2013.01.019)

Fátima LA, Baruselli PS, Gimenes LU, Binelli M, Rennó FP, Murphy BD \& Papa PC 2013 Global gene expression in the bovine corpus luteum is altered after stimulatory and superovulatory treatments. Reproduction Fertility and Development 25 998-1011. (doi:10.1071/ rd12155)

Grasselli F, Basini G, Bussolati S \& Bianco F 2005 Cobalt chloride, a hypoxia-mimicking agent, modulates redox status and functional parameters of cultured swine granulosa cells. Reproduction Fertility and Development 17 715-720. (doi:10.1071/RD05059)

Hoffmann B, Büsges F, Engel E, Kowalewski MP \& Papa P 2004 Regulation of corpus luteum-function in the bitch. Reproduction in Domestic Animals 39 232-240. (doi:10.1111/j.1439-0531. 2004.00508.x)

James DE, Brown R, Navarro J \& Pilch PF 1988 Insulin-regulatable tissues express a unique insulin-sensitive glucose transport protein. Nature 333 183-185. (doi:10.1038/333183a0)

Kim E, Seok HH, Lee SY, Lee DR, Moon J, Yoon TK, Lee WS \& Lee KA 2014 Correlation between expression of glucose transporters in granulosa cells and oocyte quality in women with polycystic ovary syndrome. Endocrinology and Metabolism 29 40-47. (doi:10.3803/ EnM.2014.29.1.40)

Klip A \& Pâquet MR 1990 Glucose transport and glucose transporters in muscle and their metabolic regulation. Diabetes Care 13 228-243. (doi:10.2337/diacare.13.3.228)

Klip A, Volchuk A, He L \& Tsakiridis T 1996 The glucose transporters of skeletal muscle. Seminars in Cell and Developmental Biology 7 229-237. (doi:10.1006/scdb.1996.0031)

Kowalewski MP 2014 Luteal regression vs prepartum luteolysis: regulatory mechanisms governing canine corpus luteum function. Reproductive Biology 14 89-102. (doi:10.1016/j.repbio. 2013.11.004)

Kowalewski MP, Michel E, Gram A, Boos A, Guscetti F, Hoffmann B, Aslan S \& Reichler I 2011 Luteal and placental function in the bitch: spatio-temporal changes in prolactin receptor (PRLr) expression at dioestrus, pregnancy and normal and induced parturition. Reproductive Biology and Endocrinology 9 109. (doi:10.1186/14777827-9-109)

Kowalewski MP, Schuler G, Taubert A, Engel E \& Hoffmann B 2006 Expression of cyclooxygenase 1 and 2 in the canine corpus luteum during diestrus. Theriogenology 66 1423-1430. (doi:10.1016/j. theriogenology.2006.01.039)

Lagathu C, Bastard JP, Auclair M, Maachi M, Capeau J \& Caron M 2003 Chronic interleukin-6 (IL-6) treatment increased IL-6 secretion and induced insulin resistance in adipocyte: prevention by rosiglitazone. Biochemical and Biophysical Research Communications 311 372-379. (doi:10.1016/j.bbrc.2003.10.013)

Lima GA, Anhê GF, Giannocco G, Nunes MT, Correa-Giannella ML \& Machado UF 2009 Contractile activity per se induces transcriptional activation of SLC2A4 gene in soleus muscle: involvement of MEF2D, HIF-1a, and TRalpha transcriptional factors. American Journal of Physiology: Endocrinology and Metabolism 296 E132-E138. (doi:10.1152/ajpendo.90548.2008)

Marette A, Richardson JM, Ramlal T, Balon TW, Vranic M, Pessin JE \& Klip A 1992 Abundance, localization, and insulin-induced translocation of glucose transporters in red and white muscle. American Journal of Physiology 263 C443-C452.

Mariani TC, do Prado C, Silva LG, Paarmann FA, Lima MC, Carvalho I, Campos DB, Artoni LP, Hernandez-Blazquez FJ \& Papa PC 2006 Immunohistochemical localization of VEGF and its receptors in the corpus luteum of the bitch during diestrus and anestrus. Theriogenology 66 1715-1720. (doi:10.1016/ j.theriogenology.2006.02.030)
Metzen E, Zhou J, Jelkmann W, Fandrey J \& Brune B 2003 Nitric oxide impairs normoxic degradation of HIF-1alpha by inhibition of prolyl hydroxylases. Molecular Biology of the Cell 14 3470-3481. (doi:10.1091/mbc.E02-12-0791)

Nishimoto H, Matsutani R, Yamamoto S, Takahashi T, Hayashi KG, Miyamoto A, Hamano S \& Tetsuka M 2006 Gene expression of glucose transporter (GLUT) 1, 3 and 4 in bovine follicle and corpus luteum. Journal of Endocrinology 188 111-119. (doi:10.1677/ joe.1.06210)

Nishimura R \& Okuda K 2015 Multiple roles of hypoxia in ovarian function: roles of hypoxia-inducible factor-related and -unrelated signals during the luteal phase. Reproduction Fertility and Development 28 1479-1486. (doi:10.1071/RD15010)

Okkens AC, Bevers MM, Dieleman SJ \& Willemse AH 1990 Evidence for prolactin as the main luteotrophic factor in the cyclic dog. Veterinary Quarterly 12 193-201. (doi:10.1080/01652176.1990. 9694266)

Onclin K, Verstegen JP \& Concannon PW 2000 Time-related changes in canine luteal regulation: in vivo effects of LH on progesterone and prolactin during pregnancy. Journal of Reproduction and Fertility 118 417-424. (doi:10.1530/reprod/118.2.417)

Papa PC \& Hoffmann B 2011 The corpus luteum of the dog: source and target of steroid hormones? Reproduction in Domestic Animals 46 750-756. (doi:10.1111/j.1439-0531.2010.01749.x)

Papa PeC, Sousa LM, Silva RoS, de Fátima LA, da Fonseca VU, do Amaral VC, Hoffmann B, Alves-Wagner AB, Machado UF \& Kowalewski MP 2014 Glucose transporter 1 expression accompanies hypoxia sensing in the cyclic canine corpus luteum. Reproduction 147 81-89. (doi:10.1530/REP-13-0398)

Pfaffl MW 2001 A new mathematical model for relative quantification in real-time RT-PCR. Nucleic Acids Research 29 e45. (doi:10.1093/ nar/29.9.e45)

Poletto AC, David-Silva A, Yamamoto AP, Machado UF \& Furuya DT 2015 Reduced Slc2a4/GLUT4 expression in subcutaneous adipose tissue of monosodium glutamate obese mice is recovered after atorvastatin treatment. Diabetology and Metabolic Syndrome 7 18. (doi:10.1186/ s13098-015-0015-6)

Purcell SH, Chi MM \& Moley KH 2012 Insulin-stimulated glucose uptake occurs in specialized cells within the cumulus oocyte complex. Endocrinology 153 2444-2454. (doi:10.1210/ en.2011-1974)

Ramakers C, Ruijter JM, Deprez RH \& Moorman AF 2003 Assumption-free analysis of quantitative real-time polymerase chain reaction (PCR) data. Neuroscience Letters 339 62-66. (doi:10.1016/S0304-3940(02)01423-4)

Royer C, Lachuer J, Crouzoulon G, Roux J, Peyronnet J, Mamet J, Pequignot J \& Dalmaz Y 2000 Effects of gestational hypoxia on mRNA levels of Glut3 and Glut4 transporters, hypoxia inducible factor-1 and thyroid hormone receptors in developing rat brain. Brain Research 856 119-128. (doi:10.1016/S00068993(99)02365-3)

Sakagami H, Makino Y, Mizumoto K, Isoe T, Takeda Y, Watanabe J, Fujita Y, Takiyama Y, Abiko A \& Haneda M 2014 Loss of HIF-1 $\alpha$ impairs GLUT4 translocation and glucose uptake by the skeletal muscle cells. American Journal of Physiology: Endocrinology and Metabolism 306 E1065-E1076. (doi:10.1152/ ajpendo.00597.2012)

Silva JL, Giannocco G, Furuya DT, Lima GA, Moraes PA, Nachef S, Bordin S, Britto LR, Nunes MT \& Machado UF 2005 NF-kappaB, MEF2A, MEF2D and HIF1-a involvement on insulin- and contraction-induced regulation of GLUT4 gene expression in soleus muscle. Molecular and Cellular Endocrinology 240 82-93. (doi:10.1016/j.mce.2005.05.006)

Slot JW, Geuze HJ, Gigengack S, James DE \& Lienhard GE 1991 Translocation of the glucose transporter GLUT4 in cardiac myocytes of the rat. PNAS $\mathbf{8 8} 7815-7819$. (doi:10.1073/pnas.88.17.7815) 
Tarhonskaya H, Hardy AP, Howe EA, Loik ND, Kramer HB, McCullagh JS, Schofield CJ \& Flashman E 2015 Kinetic investigations of the role of factor inhibiting hypoxia-inducible factor (FIH) as an oxygen sensor. Journal of Biological Chemistry 290 19726-19742. (doi:10.1074/ jbc.M115.653014)

Uldry M \& Thorens B 2004 The SLC2 family of facilitated hexose and polyol transporters. Pflügers Archiv: European Journal of Physiology $\mathbf{4 4 7}$ 480-489. (doi:10.1007/s00424-003-1085-0)
Wang Y, Qu Y, Zhang XL, Xing J, Niu XL, Chen X \& Li ZM 2014 Autocrine production of interleukin- 6 confers ovarian cancer cells resistance to tamoxifen via ER isoforms and SRC-1. Molecular and Cellular Endocrinology 382 791-803. (doi:10.1016/ j.mce.2013.10.029)

Zhang JZ, Behrooz A \& Ismail-Beigi F 1999 Regulation of glucose transport by hypoxia. American Journal of Kidney Diseases 34 189-202. (doi:10.1016/S0272-6386(99)70131-9)

Received in final form 3 September 2016

Accepted 27 September 2016

Accepted Preprint published online 27 September 2016
Published by Bioscientifica Ltd. 